\title{
LA TEORÍA DE LA EDUCACIÓN EN LA ENCRUCIJADA
}

\section{Theory of Education at the crossroads}

Joaquín GARCÍA CARRASCO y Ángel GARCÍA DEL DUJO

Universidad de Salamanca. Facultad de Educación. Departamento de Teoría e

Historia de la Educación. Paseo de Canalejas, 169. 37008 Salamanca.

carrasco@usal.es,agd@usal.es

Fecha de aceptación definitiva: marzo de 2002

BIBLID [(1130-3743) 13, 2001, 15-43]

RESUMEN

El mundo parece estar en una encrucijada; también la educación y la reflexión sobre educación. Su observación y tratamiento aconsejan encontrar claves de comprensión de la estructura y patrón global de los procesos educativos.

Entienden los autores que uno de los hándicaps de la Teoría de la Educación viene dado por la identificación y reducción del proceso educativo al proceso de enseñanza-aprendizaje en contextos institucionales. De esta manera no disponemos de una teoría unificada de la educación que proporcione el soporte necesario para pensar y hacer educación para el conjunto de espacios o comunidades donde se produce.

Para ello proponen los autores, en vez de descomponer el proceso educativo, deconstruir los numerosos estratos que la evolución cultural ha ido creando hasta llegar al sustrato más básico del proceso educativo en la especie humana.

Palabras clave: Teoría de la Educación, proceso educativo, proceso de enseñanza-aprendizaje, procesos primarios de formación. 
The world resembles to be at a crossroads; the education and the reflection about the education too. Its observation and treatment advise, at the same time that they let, finding structure's comprehension keys and educational process' global pattern.

The authors understand one of the Theory of Education handicap in this crossroads comes from the educational process' identification and reduction to the process of teaching-learning in the institutional context. By this way we haven't an unified theory of the education which provides the necessary support in order to think and do education to the whole of the spaces or communities where it happens.

For that the authors propose, instead of breaking down the educational process, unbuild the several strata that the cultural evolution has gone creating until arrive at the most basic stratum of the educational process in the human species.

Key words: Theory of Education, educational process, teaching-learning process, primay processes of formation.

Es muy usual ver e interpretar la historia y evolución del ser humano en términos de complejidad, de sucesos, acontecimientos y fenómenos, internos y externos, que han producido en los sistemas físicos, biológicos y sociales sucesivas reestructuraciones cada vez más complejas; el proceso de evolución se cifraría, así, y se expresaría en estructuras biológicas y culturales de complejidad creciente (Carbonell, 2002). Si esto es así, parece lógico que atribuyamos a nuestros coetáneos en todos sus aspectos y manifestaciones, incluidos los relativos a su estructura y dinámica sociocultural, los mayores niveles de complejidad. Y, en efecto, éste es uno de los rasgos que con más frecuencia se predican del ser humano y de la sociedad de nuestro tiempo, hasta el punto de que el propio término ha dado pie para una nueva perspectiva de análisis de la realidad, saltando, diríamos, desde la fenomenología a la epistemología. En estos momentos sigue emergiendo y configurándose toda una corriente de pensamiento, también en educación, que gusta de calificarse precisamente de epistemología de la complejidad y a la que cada vez se adscriben más autores y propuestas (Morin, 1974). La educación y la reflexión sobre educación, decimos, no es ajena a esta corriente, con lo que estamos aceptando, entre otros muchos supuestos, que los procesos y estados educativos que protagoniza o gestiona el ser humano en estos momentos, y que en cualquier caso le conforman, se encuentran en coderiva con los procesos y estados sociales. O lo que es lo mismo, que unos y otros presentan hoy tal grado de complejidad que aconseja desechar cualquier otra perspectiva de análisis que no sea la que se corresponde con las exigencias, conceptos y planteamientos implícitos en la llamada sociedad del conocimiento, que sería hoy la propia del ser humano.

Pues bien, la pregunta es inevitable: ¿está justificado en este escenario cuestionar la situación y hablar de procesos primarios de formación?, ¿en qué sentido, 
con qué pretensiones?, ¿pueden esos procesos aportarnos algo acerca de las formas de pensamiento y acción de un ser tan complejo como nosotros que, además, se mueve en una sociedad tan compleja como la nuestra?

Para muchos la sola pregunta sigue despertando reticencias y hasta desazón. Para quienes prematuramente asignaron al ser humano un lugar de señorío en la Tierra, estos interrogantes activan automáticamente discusiones, tan largas como vanas, sobre componentes y peso específico de lo innato y adquirido, lo biológico y lo cultural, lo cultural y lo civilizatorio, mecanismos de adaptación y autonomía y otros muchos aspectos planteados siempre en términos antinómicos y de adición (Asensio, 1997), planteamientos y debates que traslucen una preocupación por no simplificar, dicen, la comprensión del ser humano, cuando en realidad manifiestan un gran interés por no "hacerle descender de peldaño". Pero no todo es futilidad en estos planteamientos, pues de alguna manera han terminado por marcar un camino a no seguir, al menos para nosotros, si no queremos que la cuestión de los procesos y patrones primarios termine en un debate más o menos nominalista.

Estamos de acuerdo en que preguntarse y hablar de procesos primarios de formación no es baladí, al contrario, esta cuestión es capaz de remover posiciones, hasta el extremo de que nosotros vemos ahí un punto de apoyo para una orientación diferente en la reflexión sobre educación, susceptible de sacar a la Teoría de la Educación de la encrucijada en que se encuentra. Pero, en vez de descomponer, proponemos retroceder en el tiempo y despojar al ser humano de las complejidades civilizatorias hasta identificar el sustrato de los procesos educativos de la especie humana en su forma primaria, por supuesto cultural y compleja. Veamos.

\section{VISTÓN GLOBAL DE LA ENCRUCIjADA}

En 1947 el humanista Jacques Maritain escribió La educación en este momento crucial. Desde la situación de la educación y de la reflexión sobre educación en nuestro entorno percibimos hoy, también, a una y a otra en una encrucijada, con toda la carga semántica que encierra esta palabra: confluencia de recorridos, momento y punto coincidente de direcciones alternativas, intersección de panoramas culturales..., pero también trampas y celadas para el pensamiento o la acción.

\subsection{Orientaciones teóricas alternativas}

En los últimos cuarenta años hemos visto afrontar la reflexión sobre la educación, dentro de la encrucijada, proponiendo la elección de varias direcciones preferentes:

- Una dirección, que podríamos llamar de perfeccionamiento de facultades específicamente humanas, planteaba la educación en un plano claramente metafísico y de absoluta generalidad. La reflexión pretendía describir el 
camino trascendental desde lo humano como especie a los ideales de humanidad, proponiendo para los individuos y los grupos un entorno de moralidad, de estética, de mentalidad, un mapa del contexto utópico en el que encontrar el sentido y la dirección para la decisión y la acción en todos los ámbitos del comportamiento del humano y entre los humanos. Esta dirección puede ser historiada desde las propuestas de la paideia griega (Jaeger, 1981) y entendida como educación para la creación de la identidad humana en todas sus facetas. Por aquí han discurrido y siguen discurriendo muchos trabajos calificados de antropologías y filosofías sobre la educación y que se interesan sobre movimientos de mentalidad colectiva y otras contingencias culturales.

- Una segunda dirección la vimos configurarse en torno a una educación para la sostenibilidad de la oportunidad socioeconómica o del progreso socioeconómico, introduciendo los conceptos de capital humano y recursos humanos como marco de referencia para la reflexión (Becker, 1964). Desde esta perspectiva se promovió un concepto de educación como inversión, pública y privada, y planificación de la formación que transformara los recursos humanos en capital y capacidad productiva, una educación susceptible de oportunidad ocupacional, un acceso a la educación como forma de participación en la distribución justa de la riqueza, una oportunidad educativa como vehículo para conseguir una oportunidad social, la formación profesional como elemento esencial de la formación integral y los fenómenos de obsolescencia de la formación respecto a la dinámica socioeconómica; junto al análisis de todos estos aspectos y problemas estaba también la vertiente de movilidad social frente a la estructuración social dominante. Dentro de la perspectiva socioeconómica y de crítica social se situaron también los análisis de la educación como aparato ideológico, en tanto que reproductor de las relaciones de dominancia cultural y de dominio de la corriente de producción. En este camino tuvieron una repercusión especial numerosos trabajos sobre la educación como sistema de reproducción social (Bourdieu y Passeron, 1977) y autores que propusieron una teoría crítica, mereciendo entre nosotros un especial recuerdo Carlos Lerena (1983).

- Una tercera dirección se orientó hacia la educación como promotora de conocimiento y de la sostenibilidad del sistema científico-tecnológico; de la educación se resaltaba el aspecto de planificación de conocimiento entre dos alternativas: planificación de la transmisión de conocimiento o planificación de la actividad de conocimiento, enseñar contenidos de pensamiento o enseñar a pensar. Al debate de estas alternativas se ha ido sumando la cuestión de decidir prioridades en los campos de conocimiento y de caracterizar el currículum que tiende al conocimiento dentro de un proceso de formación. Cada vez se fue haciendo más evidente que la dinámica social, en 
las sociedades complejas, es la propia de sociedades de conocimiento. La mentalidad tecnológica, al menos eso creemos nosotros, se introdujo en las elaboraciones teóricas sobre la educación formal o institucional dentro del supuesto de que los procesos de enseñanza-aprendizaje podían, bajo muchos aspectos, entenderse como acciones que buscan metas y, en consecuencia, aumentar su eficacia mejorando los recursos asumibles dentro, especialmente, de esos procesos de enseñanza-aprendizaje. Unos lo pensábamos así porque creíamos que la acción pedagógica debía entenderse como acción técnica (Castillejo, Vázquez, Colom y Sarramona, 1993; García Carrasco y García del Dujo, 1996); otros llevaron a cabo un enriquecedor aporte desde la percepción de la acción de formación como práctica cuya calidad únicamente es acrecentable desde la reflexión sobre la propia práctica (Gimeno Sacristán y Pérez Gómez, 1993). Se subrayaba que la mejora de la enseñanza ocurriría desde la transformación de la práctica y ésta no podría producirse sino desde la reflexión y la comprensión de la propia actividad de los docentes. La calidad de la formación no vendría desde la aplicación de principios pedagógicos sino de la energía del movimiento de renovación pedagógica de los profesionales.

- La cuarta dirección de la reflexión se orientaba hacia la sostenibilidad de la propia organización democrática de la convivencia social. Dado que esta forma de organización se fundamenta en la persuasión y el consenso, la energía ha de tomarse del flujo constante de información y del mantenimiento de la acción comunicativa; el acceso a la información y la participación en el debate y en el quehacer social han compuesto el embrión del concepto de ciudadanía y la idea de una ciudadanía inspirada en valores compartidos constituiría el meollo para una teoría de la educación (Ortega Ruiz y Mínguez Vallejos, 2001).

Con frecuencia todas estas perspectivas eran presentadas en el momento de la confrontación dialéctica como mutuamente excluyentes por incompatibles. Recuérdese a este respecto la contundencia del corolario infinidad de veces repetido: toda acción pedagógica es acto de violencia simbólica. La perspectiva temporal se ha encargado de hacerlas, hoy, necesariamente complementarias.

\subsection{Problemas educativos graves que no son escolares}

Junto a estas cuatro direcciones cruciales - podría señalarse, sin duda, alguna más y también desgajar otras de las ya mencionadas (muchos de los autores en los que ahora estamos pensando quedan incluidos en la obra coordinada por Ortega Ruiz, 1997) —, han aparecido cuestiones socioculturales que sitúan, de nuevo, a la educación en el foco de la encrucijada, volviendo a plantear las cosas ab initio, es 
decir, quedando obligados de alguna manera a afrontar planteamientos radicales, deconstrucciones o como quiera que se les llame.

Una de ellas tiene origen en la pregunta radical sobre la sostenibilidad del devenir humano, puesto que ninguna de las orientaciones anteriores tomó en consideración otra cosa que el "progreso" de la acción humana y no su viabilidad. No se trata únicamente de un nuevo campo o tema, la ecología, ni de un nuevo contenido para la formación, la educación ambiental, pues nos enfrentamos a un replanteamiento global de la acción y de la reflexión sobre la acción humana, incluso de la reflexión de los humanos, cuando ese mundo no es un mundo metafísico e inmaterial sino "corporal", el mundo más propio de la vida, el mundo de los seres vivos, la biosfera.

Junto a ella, otras muchas controversias alimentan el diálogo social y cuyo origen estriba en situaciones conflictivas o problemáticas que, al final, confluyen en valoraciones de mala educación: el racismo y la xenofobia, los fundamentalismos, las drogodependencias, la violencia relacional que aflora en los malos tratos, acosos sexuales y morales, violencia escolar... la insolidaridad, la irresponsabilidad... incluso el deterioro ambiental y todas las formas de desconsideración con el propio cuerpo, como los malos hábitos sanitarios, formas deficientes de consumo y de ocio... la hipertensión ocupacional y el aumento del estrés, la distorsión de las tramas emocionales y el padecimiento afectivo... El carácter problemático de estas situaciones es vivido como fracaso educativo, como infortunios educacionales de una sociedad. Es obvio que no se trata de un fracaso escolar, sino de un fracaso cultural; no de un fracaso de enseñanza, sino de un fracaso de comprensión y de acción.

Y a todo este panorama de debate se suma el relativo al papel de la Pedagogía como campo de conocimiento del que se supone deben obtenerse criterios para decidir en el centro de la encrucijada, criterios de selección para los caminos a tomar, al menos para pensar sobre la educación, porque cabe entender que estos problemas sociales constituyen para la comunidad un gigantesco problema educativo.

\subsection{La culpa la tienen la pedagogía y los pedagogos}

La sociedad moderna, convencida de que la educación constituía no sólo un aspecto fundamental del modo de vida de los humanos, sino también un recurso básico para el sostenimiento de sus propósitos y aspiraciones, hizo de ella objetivo político y proyecto colectivo, cuyo cuerpo social toma la forma de sistema de enseñanza. Los procesos educativos que caracterizan el etograma de la especie humana fueron quedando subsumidos, en los tiempos modernos, dentro de los sistemas de acción pedagógica, llamando la atención sobre todo los sistemas sociales de enseñanza-aprendizaje; las cuestiones de etograma estaban llamadas a desvanecerse progresivamente ante la parafernalia institucional de los procesos de enseñanza-aprendizaje. La educación pasó así de ser percibida como un ámbito natural de acción dentro del etograma de la especie a ser un proceso dentro de la 
responsabilidad del ețograma social. En consecuencia, la percepción de los infortunios educativos corren el riesgo de ser interpretados como fracasos pedagógicos, poniéndose en cuestión no ya la ambigüiedad y equivocidad de la dinámica social, "el malestar de la cultura" (Freud, 1986), sino la ineficacia del sistema de los sistemas educativos y la inoperancia del pensamiento y acción pedagógicos. Asistimos a un crecimiento de crítica a la calidad de la enseñanza y, en paralelo, a un recrudecimiento de la crisis de confianza y de legitimidad de la Pedagogía, un aumento del desgarre y rompimiento de las relaciones entre la función pedagógica de los enseñantes y la de los pedagogos (Ruiz Paz, 1999; Enkvist, 2000; San José, 2001), un escenario de incomprensión de unos y otros.

Al mismo tiempo, cada vez es más clara la opinión entre los actores del sistema de que, para que su intervención sea viable, el sujeto debe llegar con un nivel de educación mínima, un nivel mínimo de educación que permita la acción pedagógica que el sistema estipula. Ya no se trata sólo de conocimientos mínimos exigibles para el inicio de una planificación curricular, sino de calidades comportamentales que hagan sostenible el estado de cosas en las que consiste el propio sistema, es decir, la relación pedagógica. El sistema es inviable, en opinión de los profesores, sin ese nivel mínimo de educación; para que inicie su funcionamiento el motor interior del sistema se requiere de un motor de arranque en el exterior en perfectas condiciones de funcionamiento. De lo contrario, se generarán situaciones insostenibles. Esta insostenibilidad se indica, en forma extrema, bajo el problema de la violencia escolar y, de manera menos dramática, como carencia de actitudes para el trabajo escolar. El Estado se lo plantea como objetivo político de calidad de la enseñanza, los profesionales de la enseñanza como inviabilidad de ciertos criterios pedagógicos y la sociedad como inviabilidad de ciertos modos de ser y de actuar, que aparecen como "caracteres" de generaciones contemporáneas.

El conjunto de cuanto hemos descrito en este epígrafe representa una síntesis de la encrucijada, de la dificultad para encontrar un camino a seguir, porque cada dirección o aspecto del problema se presenta como alternativa; dicho en otros términos, las direcciones posibles aparecen como incompatibles y la inmensa mayoría de las propuestas de innovación, frente a las convenciones y convencimientos más arraigados, tienen todos los visos de experimentos sin garantías. De ahí que la innovación, para muchos, en este estado de cosas, no tenga el menor aliciente.

Todos parecemos estar en la encrucijada. El riesgo más evidente es culpabilizarnos unos a otros de la desorientación. Dilucidar la encrucijada supondría cartografiar de nuevo fenomenológica y multidisciplinarmente la educación. En este texto nos contentaremos con reflexionar desde la perspectiva de un área de conocimiento, Teoría de la Educación, que tiene la obligación y responsabilidad de "actualizar" el contenido de sus disciplinas de manera que respondan a un plan razonable de formación y a las exigencias de una sociedad y unos profesionales que, antes de nada y según sus propias manifestaciones, pretenden tomar el proceso integral de la formación de los humanos como tema y como problema, mucho antes, por supuesto, de verlo cristalizar en forma de instituciones específicas de formación e hipertrofiarse 
en forma de sistema de enseñanza, y que entienden que esa visión previa o primera de la educación puede constituir un marco o perspectiva curricularmente útil para quienes en última instancia pretenden convertir acciones de formación en ocupaciones profesionales.

\section{La Teoría de la Educación en la ENCRUCijada}

La experiencia y observación de esta encrucijada proporciona al estudioso de la educación claves que ayudan a comprender la estructura y el patrón de la urdimbre de los procesos educativos. A continuación indicaremos algunos componentes y orientaciones que los autores consideran especialmente relevantes para ese trabajo de clarificación, aunque sea provisional, en el torbellino de estímulos y contingencias culturales de nuestro tiempo.

\subsection{Teoria pública y teoría privada de la educación}

En el afán y necesidad que toda disciplina tiene de buscar nuevos campos y perspectivas de indagación, la Teoría de la Educación no ha sido una excepción, aunque para muchos el problema se encuentre precisamente en las distintas orientaciones que ha adoptado esa pretensión. Así, durante mucho tiempo lo que podríamos denominar teoría pública acerca de la educación consistió, realmente, en la integración de un conjunto de principios prácticos justificados y argumentados desde convicciones filosóficas generales o, más tarde, desde los conocimientos científicos considerados convergentes. Es decir, la teoría de la educación se generaba cuando el filósofo o el científico convertían la educación en objeto de sus consideraciones. En infinidad de casos se trató de una ocupación marginal, una especie de servicio intelectual vicario, un favor llevado a cabo por quienes conocían la disciplina de la filosofía y de la ciencia y estaban habituados a la metodología de la argumentación, además de disponer de una cierta "información" pertinente. Un proceso similar ocurrió a medida que se fueron instituyendo otros campos científicos de proximidad, como la psicología y la sociología. Los educadores recibían de los planteamientos generales de esas disciplinas respuestas a preguntas acerca del proceso de la educación, que unos y otros transformaban posteriormente en criterios desde los que construir estrategias para promoverlo. El educador apreciaba la calidad interna de tales elaboraciones al tiempo que padecía la enorme distancia que mediaba entre aquellos "textos" y las urgencias de las «situaciones prácticas" en las que se veía envuelto. Las preocupaciones y argumentos de los educadores se contenían en el ámbito de la "cultura educacional privada", que formaba parte de las conversaciones. La distancia entre la teoría pública y la teoría privada, entre el problema teórico y el problema práctico, era la misma distancia que mediaba entre textos y conversaciones. 


\subsection{Teoria de la acción y del proceso educativos}

Desde que la educación se transformó en un proyecto colectivo, en objetivo público, y tomó cuerpo social en forma de sistema de instituciones, la educación como tema de reflexión y como acción se convierte en la ocupación social de muchas personas, en actividad profesional. Ahora, disponer de teoría, de principios argumentados desde los que decidir la acción se torna una necesidad que se trata de satisfacer desde el interior de ese cuerpo profesional. Muchos de ellos sintieron que los interrogantes que se planteaban desde la práctica en la que se encontraban inmersos eran capaces de satisfacer sus mejores exigencias intelectuales. Muchos hemos sentido la necesidad de razonar y argumentar los procesos educativos como una necesidad vital, porque todo hombre en su sano juicio ha de estar en condiciones de dar cuenta y razón de sus actuaciones. Y porque una manera de preservar la salud mental de un profesional de la acción pedagógica, en cualquiera de sus formas, consiste en alimentar esa capacidad de razonar la acción, independientemente del valor social asignado a tal acción. Los modelos dominantes de razonamiento seguían siendo el filósofo y el científico. Investigar la educación se convirtió en una indagación de sistemas filosóficos influyentes y de campos científicos próximos. Quienes se inclinaban por la reflexión desde la acción orientaban sus lecturas hacia la Sociología, mientras otros, más interesados por los procesos que tenían lugar en los sujetos particulares, lo hacían por la Psicología. Era lógico, si para unos tenían importancia, por ejemplo, las relaciones en el aprendizaje y para otros, también por ejemplo, lo tenían las motivaciones; unos se preguntaban cómo tiene lugar la relación, otros qué es la motivación. Todos pensábamos que tanto el educador como el pedagogo habrían de ser capaces de alimentar de razón la práctica; todos nos esforzábamos en buscar "utilidades" racionales, piezas para un mosaico teórico que nos permitiera ver con claridad la práctica. Se rastreaban los argumentos completos ya fuera porque versaban sobre cuestiones directamente relacionadas con la formación, por ejemplo, el estudio filosófico de la cultura, o porque eran fácilmente derivables a cuestiones de formación, por ejemplo, el estudio de la motivación en Psicología y su proyección a tareas escolares. A veces se buscaban las calidades de las argumentaciones en teoría de la educación midiéndolas por el nivel de autoridad de las fuentes, dándose una cierta coincidencia entre las grandes autoridades de la Filosofía, la Sociología, la Psicología y las grandes argumentaciones pedagógicas. Se producía un efecto inverso para el observador. Mientras el pedagogo encontraba la teoría de la educación como ocupación marginal en el conjunto del medio filosófico o científico, los filósofos y científicos encontraban marginalidad, valor residual, en el tratamiento de los temas dentro del conjunto del medio pedagógico.

Para muchos profesionales de la educación el trabajo consistía en un acarreo de conceptos en tanto que herramientas para la reflexión, en lo que tenían de términos de una teoría pero también de palabras - fin, modelo, objetivo, sistema, estímulo, esquema, consenso, acción comunicativa, negociación...-, para intentar 
comprender mejor y describir con mayor fidelidad los sucesos y acontecimientos que tienen lugar en el proceso de la educación; se buscaba por esta vía concordancia teórica con otros campos y mayor elaboración del código lingüístico disponible. Esto se apreció, entre nosotros y en notables ejemplos de fuera, respecto de la filosofía analítica (Esteve, 1979; Peters, 1969), de la teoría general de sistemas y la teoría de la información (Colom, 1982; Sanvisens, 1983; Puig, 1986), y hoy en relación con la posmodernidad y la teoría del caos (Colom, 2002). En algunos casos, hemos de reconocer, se trata de un proceso "incompleto" de transcripción teórica o de "reducción de teorías" a procesos de educación. Proceso incompleto, porque el ciclo de vida de esta actividad de incursión y acarreo fue muy corto, medido en años de prevalencia, en continuidad de publicaciones, en cantidad de estudiosos adscritos a una misma línea de indagación y, además, era corto en la profundidad con la que se incidía teóricamente en cada sistema de pensamiento. Pero, sobre todo, se detiene el proceso en la aportación de perspectiva y no se remata la construcción de una teoría de la educación dentro de ella. Podríamos afirmar que esos esfuerzos tenían la forma de una introducción a la construcción de una teoría de la educación desde tal o cual perspectiva. En este momento, volvemos a tener oportunidad de demostrar hasta dónde somos capaces de incorporar e incorporarnos al entorno de las ciencias de la comunicación y del conocimiento o de las tecnologías de la información y la comunicación, para dentro de ellas promover elaboración teórica. Esta búsqueda de fragmentos teóricos no se funda meramente en la presunción de que, si se encuentran principios generales, se obtendrá fuente de eficacia práctica; también contiene en nosotros una voluntad de encontrar recursos para la racionalidad de la propia acción, alimentada por un cierto espíritu crítico respecto a las calidades de la propia reflexión. Sobre todo cuando la reflexión no incide sobre la práctica en su inmediatez sino sobre la legitimidad de preguntas como ¿qué es esto de la educación?, ¿por qué esto de la educación?, ¿qué cosas pasan cuando tiene lugar la educación?, ¿cómo somos para que nos pasen estas cosas?

Si anteriormente se percibía lejana y distante la propuesta del filósofo respecto a la expectativa del educador práctico, ahora la lejanía se atribuye a las propuestas del teórico de la educación y las expectativas del docente. La primera forma de distancia parecía entre gente de dentro y gente de fuera de las prácticas educativas; ahora parece que se trata de distancia entre gentes de dentro, entre una teoría académica y una necesidad pedagógica práctica. Las profesiones pedagógicas se han diversificado; en todas ellas se plantean cuestiones de relación entre teoría y práctica, pero donde parece más convulsivo ese distanciamiento es entre teóricos de la educación y docentes; y, dentro de los académicos, entre diferentes posiciones teóricas sobre la educación. Lo que en su momento llevó a cuestionar de manera radical si puede existir alguna dependencia entre las prácticas educativas y las disciplinas académicas (Carr, 1996).

Probablemente la práctica se encuentre, siempre, un punto más allá de toda teoría; pero la teoría, las razones, forman parte necesaria de la fuente con la que 
aclaramos la práctica. Probablemente no sea la única fuente, porque entre los motivos y las formas de la acción se entreveran las emociones y las identidades amasadas con "historias" experienciales; por ello, aunque estudiamos e investigamos para comprender, a medida que aumenta la comprensión no lo hacen en la misma proporción las garantías de la acción. Pero sostener el afán por comprender sigue siendo una meta de calidad propuesta a todo proceso de formación. Esta meta, hoy, sentimos que nos obliga a introducir un pequeño viraje en nuestro afán por comprender la educación de los humanos.

\subsection{Teoría de la Educación desde la inmersión en la práctica docente}

Si tomamos la totalidad del ámbito de la educación, la globalidad del proceso de educación dentro de la especie humana y la globalidad de las ocupaciones que definen la actividad pedagógica en las sociedades actuales, docentes y no docentes, quienes definimos nuestra práctica social dentro de estas tareas tenemos necesidad de comprender el proceso educativo en su conjunto como marco para la comprensión del sentido de los procesos prácticos educativos en los que nos vemos envueltos. La comprensión del fenómeno educativo en su conjunto y en sus generalidades respecto a cada categoría de problemas constituye un aspecto fundamental de nuestra práctica teórica y de la conceptualización de nuestras propias actividades, docentes y no docentes, de las denominadas formales y de las otras. Mucha de esa conceptualización se ha reflejado en documentos públicos que alimentan multitud de circuitos de comunicación de infinidad de categorías educadores; otra cosa diferente es que esa teorización se haya incorporado como información relevante dentro de los gremios de filósofos y científicos.

Pero dentro de esa intencionalidad global teórico-práctica, por la magnitud pública del sistema que la sostiene, se destaca el sistema de enseñanza y el conjunto de personas y prácticas que lo sustentan: las teorías y las prácticas de los profesores. En este segundo caso, vuelven a plantearse dos cuestiones: el sentido de los componentes de la teoría global sobre los procesos de educación — podríamos calificarlo de ámbito disciplinar sobre la educación- y el perfeccionamiento de la racionalidad, en el sentido de eficacia práctica, de las teorías que emplean los profesores. El problema estriba en que, en algunos ámbitos, especialmente en el anglosajón, el concepto de teoría de la educación, "una auténtica ciencia de la educación, como ciencia crítica de la educación, una investigación educativa ..." se ha planteado con el evidente sesgo de diseñarla "para potenciar profesionalmente a los profesores". Un ejemplo claro es la interesante obra de Wilfred Carr Una teoria para la educación. Hacia una investigación educativa crítica. En ella construir "teoría de la educación" es promover "el perfeccionamiento de la eficacia práctica de las teorías que emplean los profesores". Desde esta perspectiva una "teoría de la educación que eche sus raíces en el saber necesario para resolver los problemas educativos» no puede transformar estos problemas (educativos-institucionales-docentes) en 
cuestiones teóricas, porque los priva de su carácter práctico; tampoco existen "disciplinas educativas" propiamente tales por el mismo motivo, ni pueden convertirse estos problemas en la vía para el rastreo-acarreo de cuestiones filosóficas, sociológicas o psicológicas...; los problemas de esta teoría "únicamente pueden plantearlos y resolverlos los profesionales de la educación”. Los teóricos de la educación no pueden ser inspectores de la teoría y la práctica educativa. Es "la práctica la que determina el valor de cualquier teoría de la educación, en vez de que la teoría determine el valor de cualquier práctica educativa". "No existen teorías de la educación independientes de las que estructuran y guían estas prácticas"; la única teoría de la educación legítima "consiste en desarrollar teorías de la práctica intrínsecamente relacionadas con las propias explicaciones que los profesionales dan de lo que están haciendo". Hay que evitar el miedo a "prescindir de las disciplinas académicas".

Ninguna teoría de la educación que se tome en serio a sí misma puede limitarse al discurso oficial de las disciplinas teóricas ni contentarse con definir otra categoría académica en la que pueda depositarse sin problema otro cuerpo de información teórica, sino que debe esforzarse por examinar la mayor o menor adecuación de los conceptos y teorías que se materializan en el lenguaje de la práctica educativa, articulando la relación entre el discurso educativo y las realidades que este discurso pretende asimilar y describir. Esto no supone transformar la teoría de la educación en una mezcla desestructurada de teoría y práctica ni implica que la teoría de la educación deba restringirse al "aula". Menos aún significa que la filosofía, la psicología y la sociología carezcan de importancia al respecto y haya que oponerse a ellas (Carr, 1996, 62).

Para quienes estamos inmersos en prácticas educativas de diferente índole, envueltos en los problemas que plantea y se formulan desde esa práctica, advertimos con toda claridad que muchas disciplinas académicas se construyen desde fuera de ella, pero también advertimos la cantidad de recursos que contienen para nuestra propia reflexión desde la práctica. Precisamente desde la práctica nos parece evidente que la práctica no se aclara a sí misma, sino en la medida en que se es teóricamente activo. Pero, sobre todo, que la actividad teórica en la práctica plantea preguntas cuya respuesta no se puede encontrar en la práctica ni, de encontrarse respuestas, tienen éstas por qué redundar en la eficacia directa de las propias prácticas, aun cuando su indagación sí aumenta la comprensión global del proceso al que la práctica pertenece. Los ejemplos abundan por doquier; la mejora de la educación ambiental y la mejora de la práctica de mostrar el lenguaje de la naturaleza nos aboca a la pregunta acerca de por qué el proceso de la educación se hace patente únicamente en la especie humana, ¿qué tiene la especie humana que no tienen los demás seres vivos?, ¿por qué los humanos son educables?, ¿qué de la experiencia del mundo de la vida modifica nuestro comportamiento en ese mundo?, ¿cómo se preserva la experiencia de una generación a otra?, cuestiones todas ellas que muchos de los que estamos inmersos en la práctica de la educación nos formulamos. Estas preguntas no nacen directamente desde la práctica inmediata 
como quehacer ni su respuesta revierte en ella como utilidad inmediata. La práctica de viajar a la luna no puede abandonar a la responsabilidad de la astrofísica la creación de un conocimiento útil que mejore las garantías para la realización del viaje, pero nadie puede minusvalorar la utilidad de los conocimientos de astrofísica para quienes han de ser prácticos de la astronáutica. El problema no es solamente cómo construir una teoría que brote de la práctica, sino también cómo alimentar la práctica de la teoría y la práctica de construir marcos de referencia, cuando esa práctica forma parte integral de un modo de ser humano, del que la práctica concreta no es más que un caso. ¿Cómo prevenir la reflexión sobre un incidente práctico, por ejemplo la conducta violenta de un alumno en clase, de forma que nos encuentre, en lo posible, preparados, si en el incidente mismo de lo único de que no dispondremos es de tiempo para la reflexión?

Aunque los ejemplos vuelvan a ser de "aula", cualquier educador profesionalmente implicado en la práctica y teóricamente activo se siente atraído por problemas generales sobre la educación, arrastrado a ellos precisamente por la propia calidad de su práctica teórica; además, creemos que ésta es la situación de toda práctica reflexiva de calidad, pues esta perspectiva es la que otorga valor cultural, formativo, para todos los prácticos a los productos que la ciencia, la filosofía y las ciencias, originan y que los prácticos integran en cuanto enriquecedores del marco de referencia global de su propia actividad. La polarización en las exigencias de la práctica inmediata es, creemos, una de las razones que marginaron del enriquecimiento cultural global a muchos maestros y a muchos pedagogos.

La comunicación, comprensión y mutuo enriquecimiento entre diferentes profesionales de la educación, investigadores, estudiosos y prácticos, es ciertamente un problema de la teoría, pero también lo es de las relaciones prácticas, mejor dicho no relaciones, entre unos y otros, relaciones que deberían cambiar las prácticas y las teorías de unos y otros. Por ejemplo, los pedagogos, docentes y no docentes, advertimos en la práctica el papel que juegan los componentes emocionales en los complejos comportamentales en los que nos vemos envueltos y encontramos programas disciplinares enteros que se suponen versan sobre la actividad mental de los seres humanos y que ni siquiera contienen una palabra sobre estos aspectos. La práctica y la teoría se separan por la forma de teorizar y practicar y por la manera de organizar el trabajo pedagógico dentro de un sistema tan complejo como el conjunto de los proyectos institucionales educativos del sistema social.

Si las cosas acontecieran de otra manera, las buenas prácticas, los movimientos de innovación pedagógica "Subirían" hacia la teoría académica componiendo argumentos de prueba, dado que entre los modos de formación que la especie humana incorpora se encuentran la reflexión sobre la práctica, la imitación, la inmersión en actividades colectivamente asumidas, la preservación de la experiencia en narraciones y textos... Pareciera que la única experiencia no transmisible es la práctica de las acciones de formación. El problema central de esta discusión se centra en la posibilidad de construir una teoría de la educación que tenga la función de prevenir y preparar el ejercicio, imprescindible, de la reflexión 
teórica en la práctica. La experiencia de esta reflexión, en tanto que pedagogos inmersos en la práctica de la reflexión sobre la educación, es la que sintetizamos en las páginas que siguen.

\section{EL OJO DEL TEÓRICO DE LA EDUCACIÓN}

Una opción intelectual importante que tomamos en este trabajo es reflexionar sobre la educación tomando en cuenta las situaciones en las que tiene lugar, y con las que quedamos comprometidos, pero buscando los rasgos que comparte el proceso aunque cambien las situaciones. Este proceder estratégico no implica, necesariamente, elevar los niveles de abstracción hasta alcanzar un tratamiento metafísico del tema, como cuando se habla de la educación en general en cuanto perfeccionamiento de facultades específicamente humanas; más bien responde a la circunstancia real de la práctica en la que actuamos como agencias de educación en espacios familiares, espacios sociales, espacios escolares. Cuando sometemos todas estas situaciones a observación crítica, advertimos que el proceso educativo tiene lugar dentro de una secuencia de sucesos culturales y que en muchos aspectos coincide con ellos; pormenorizar esta perspectiva nos obliga a plantear previamente algunas cuestiones de diferente magnitud.

Si explicitamos la idea de perspectiva o punto de vista, comprobaremos que no la construimos desde la posición en un sitio; no es el lugar el elemento decisivo para la definición de una acción, sino el hecho de tener o no a disposición un núcleo de recursos intelectuales que la hacen inteligible; entre esos elementos juegan un papel fundamental las metáforas, la propia seducción de las palabras y otras muchas suposiciones. Todos ellos conforman un núcleo de inteligibilidad que funciona de manera análoga a como lo hacen los aludidos con otras denominaciones, como marco conceptual, paradigma, programa de investigación...

Ese marco de inteligibilidad, cuando pretendemos "ver" elementos reales muy pequeños, lo proporciona el "microscopio"; en cambio, cuando lo que queremos es ver lo inmensamente lejano, empleamos el marco de inteligibilidad que proporcionan los instrumentos "telescópicos". Y, cuando pretendemos ver las realidades inmensamente complejas que afrontamos en las variadas prácticas de observación en las que nos vemos envueltos, desde la calle al laboratorio, empleamos no menos variados núcleos de inteligibilidad que, de momento, denominaremos "macroscopios". Aunque hablamos de instrumentos, en todos los casos estamos ante un conjunto de supuestos básicos, sistemas de proposiciones aceptadas, compromisos intelectuales compartidos (Pérez Ransanz, 1993), circuitos privilegiados de consenso intelectual, catálogos de textos más frecuentados. No estamos sólo ante un material de información, pues esos núcleos constituyen auténticos instrumentos para la comprensión; contienen supuestos y compromisos básicos en ontología, generalizaciones simbólicas o leyes fundamentales aceptadas, procedimientos y técnicas de investigación, criterios de evaluación y corroboración, dentro de los cuales reconocemos 
formas ejemplares de plantear problemas y solucionarlos; precisamente la concreción de todos estos elementos constituye la matriz disciplinar para la actividad de conocimiento, al tiempo que proporciona el criterio desde el que elaborar los textos de las disciplinas académicas.

Pues bien, construir teoría de la educación es, al tiempo que indagación, un proceso de selección, construcción e identificación de perspectiva. Construirla desde la práctica teórica implica tomar conciencia de las distintas opciones valorando lo que incluyen y lo que dejan fuera; pero, también, estudiar la forma y medida en que perspectivas metodológicamente incompatibles pueden ser complementarias. Cualquier acontecimiento humano, por su propia complejidad, es inconmensurable desde una única perspectiva, inabarcable desde un único macroscopio. Por lo tanto, la racionalidad en el tema de la educación nos plantea una responsabilidad de perspectiva crítica, aunque con ella no agotamos nuestra responsabilidad intelectual; se requiere además una responsabilidad de crítica de perspectiva.

Y siguiendo la imagen de instrumento que hemos vinculado a la idea de macroscopio, creemos que una de las disputas importantes entre los profesionales de la educación viene siendo alimentada por un sesgo de diafragma en un macroscopio muy empleado. Al identificar educación con enseñanza-aprendizaje planificada en organizaciones institucionales, la práctica se asimila con el quehacer de los profesores; en consecuencia, la legítima teoría de la educación, aquella que beneficia y transforma la práctica, es la que genera la reflexión desde la propia práctica; los no partícipes de esa práctica padecerán de ilegitimidad teórica. Pero, si empleamos otros supuestos, todos estaremos implicados en la práctica educacional y responsabilizados en la reflexión, pudiendo beneficiarnos de reflexiones desde categorías de prácticas diferentes y evitar, al mismo tiempo, suplantar vicariamente la reflexión de una categoría diferente de actores. Digamos que será posible reflexionar actuando y estudiando, sin que ello suponga interferencia ilegítima ni en la práctica ni en la teoría. Veamos más detenidamente adónde nos conduce esta propuesta.

\section{CONSTRUCCIÓN DE UNA TEORÍA DE LA EDUCACIÓN EN LA ENCRUCIJADA}

Lo venimos diciendo reiteradamente. La importancia de los sistemas de enseñanza dentro de las tareas sociales de los Estados modernos, la importancia del proceso de formación institucionalizado para el acceso a las oportunidades sociales de carácter ocupacional y para la configuración de una participación en la dinámica ciudadana, ha situado el pensamiento sobre la educación dentro de un sesgo reflexivo que privilegia la práctica educativa institucional como objeto dominante de reflexión.

Los tres ejes fundamentales en torno a los que habitualmente se construye la teoría de la educación - sujetos culturalmente maleables, sujetos culturalmente 
dependientes y sujetos culturalmente ignorantes (Flecha, 1988) - se vieron reforzados cuando se introdujo en el contexto cultural la innovación lectoescritora y todas sus interfaces, unas lentas como la evolución del formato y las características del soporte, otras revolucionarias como la imprenta. El nuevo sistema de comunicación evoluciona en coderiva con el sistema de administración y de producción. Esta coderiva estuvo en el origen de la escuela e interviene como recurso de formación dentro de los sistemas de enseñanza; de ahí el sesgo. El sistema de las acciones de formación queda compenetrado con los procesos de enseñanza-aprendizaje y éstos con procesos característicos de transmisión de conocimiento, dentro de prácticas que caracterizan a las instituciones de formación aunque la gama tipológica de prácticas sea muy variada. Tal vez han sido la Sociología y la Psicología los campos de conocimiento de los que la teoría de la educación haya recibido mayor influencia y, en ambos casos, se ha alimentado la perspectiva escolarizada de la formación.

Probablemente la prueba definitiva del sesgo que comentamos se pueda concretar en el hecho de que todo el complejo ámbito de la formación de los humanos no institucionalizada se engloba dentro del difuso y ambiguo término de educación informal. El sesgo tiene la consecuencia de no disponer de lo que podríamos denominar una teoría unificada de la educación que no sea únicamente metafísica y que proporcione el sustrato necesario para desde él construir reflexión fundamental para el conjunto de espacios o comunidades en los que se explayan las acciones de formación. Y en nuestra opinión, la construcción de esa teoría unificada requiere de incursiones en campos de conocimiento habitualmente menos visitados.

\section{1. ¿Descomponer o retroceder?}

Un procedimiento útil para alcanzar el sustrato de los procesos educativos en la especie humana es retroceder en el tiempo, deconstruyendo las superestructuras que la evolución cultural ha ido creando, y desnudar a los seres humanos hasta encontrar los fundamentos desde los cuales la evolución dispuso los caracteres de esta especie capaz de crear e incorporar cultura. La cuestión inicial vuelve a ser, hoy, resituar el fenómeno educativo dentro del mundo de la vida de los humanos, teniendo especial sentido este propósito cuando los problemas culturales que advertimos en nuestro entorno aparecen como dramáticos problemas de educación, al tiempo que vemos que pueden sólo parcialmente aliviarse a partir de las acciones posibles en las instituciones de formación.

El punto de partida más primario y fundamental es el hecho de que tanto la creación cultural como el proceso de formación acontecen en un ser vivo cuyo modo de vida requiere de la cultura para vivir y para el que la cultura constituye su medio de vida. Su capacidad de creación cultural centra la ventaja evolutiva de la especie en tanto que favorecedora de trato específico con los ecosistemas 
susceptibles de colonizar, las transformaciones capaces de introducir en el entorno para adaptarse a él y las iniciativas a desarrollar para mantenerse. Este planteamiento nos abre el interés por fijar la posición del hombre entre los seres vivos; no sólo comprender bioetológicamente a la especie humana, nuestro parentesco biológico con los seres vivos, sino también justificar nuestra excepcionalidad. Y ello nos obliga a reflexionar la educación dentro de una propuesta de unidad psicosomática, en vez de hacerlo en la implícita dualidad cartesiana de res cogitans, res extensa (Damasio, 1996), dentro de la complejidad estructural de relaciones mentecuerpo, de la unidad vital que vive y piensa. La educación acontece como proceso en un ser vivo que está en el mundo "de cuerpo pensante".

La pregunta por el puesto del hombre en el cosmos casi siempre ha llevado en su formulación el implícito de una respuesta que situaba al hombre "por encima", como imbuido de una liberación ecológica (Rodríguez Delgado, 1972): todos los seres vivos padecen una dependencia de sus respectivos ecosistemas y, en general, de la biosfera, menos los seres humanos, que estarían dominando y pudiendo actuar sin apenas otra limitación que el seguimiento de sus más creativas y arriesgadas iniciativas de dominio de la naturaleza; y todo por aquello de que, también aquí, quien tiene la información tiene el poder y quien no parece tener límite en el conocimiento sobre el mundo tampoco parece encontrarlo en el poder sobre el mundo. Desde aquí se ha construido un humanismo de dominancia.

Pero lo que caracteriza a los seres humanos, a diferencia del resto de los seres vivos, no es aquella dominancia que criticamos, sino el hecho de que la dependencia se les convierte en responsabilidad. Demostrar esta dependencia-responsabilidad supone reconstruir nuestra relación con la Tierra dentro de un sistema de pensamiento coherente con ella, porque los hombres nos reconocemos e identificamos empleando las herramientas del pensamiento, mediante las palabras con las que conversamos, las mismas con las que pensamos. La trama primaria de la vida consiste en una propiedad, la autopoiesis, que se mantiene en toda su historia evolutiva, no obstante los cambios de estructura y de patrón; la vida comienza con ella, cuando una red de macromoléculas biógenas se clausura sobre sí misma dentro del entorno e inicia un patrón de organización que hace posible el proceso de autoconstrucción, autorregulación, autorreparación y autorreproducción (Maturana y Varela, 1990). Esta propiedad define un carácter para todo proceso de influencia, incluso de influencia dentro de comunidades humanas: el efecto en el interior de una acción desde el entorno siempre estará mediado por el estado de cosas en la propia estructura. Ésta es la condición primaria de autonomía en todo sujeto de educación.

Son muchas las tramas que recorren la vida y de las que los humanos somos partícipes, que también proporcionan la estructura y el patrón específico del modo de vida humano dentro de los cuales se configuran las formas de las interacciones, entre los humanos y con el mundo, para construir la experiencia. 


\subsection{Lo que podemos aprender en los comienzos}

La conquista del ecosistema terrestre en vez del arborícola, el bipedismo, la cerebralización (aumento del tamaño del cerebro y de la corteza cerebral) y la cultura se consideran acontecimientos clave en la evolución de la humanidad; todos esos hechos y fenómenos evolucionaron en coderiva. En los primeros pasos de la humanización, en las primeras fases de la protocultura, el hombre expresaba su genuina relación con el mundo comprendiendo sus prácticas de supervivencia, ejercitando el entendimiento de los caracteres vitales del entorno en función del correspondiente a sus necesidades corporales; diríamos que, fundiendo cultura corporal y cultura ambiental, fue creando cultura de humano. De ahí que el contexto no le aparece como escenario de su acción, sino como el medio genuino en el que se elabora una práctica con sentido. La vida se había expresado en forma de mecanismos innatos de comportamiento y estímulos desencadenadores, dentro de un proceso de biodiversificación constante. El éxito vital tenía lugar en tanto que éxito reproductivo o posibilidad de sobrevivir con el etograma de la especie (y sus cambios) dentro de un ecosistema (y sus cambios); en este contexto de interdependencia auto-ecopoiética funcionaba la lógica de la selección natural. Y no puede entenderse la vida sino en el interior de esta pertenencia al ecosistema. Entre esta rigidez inicial de interacción, aliviada por la constante biodiversificación, resultaron ventajosas las formas de locomoción de los humanos, sus cambios de forma y posición en la comunicación intraespecífica, la construcción de diseños de acción, el aprender acción por la comprensión del diseño, la preservación de la experiencia..., en definitiva, los rasgos que definen de manera primaria el comportamiento de los humanos.

Conocer con qué llegamos al mundo los humanos, con qué contamos primariamente en el mundo de la vida, creemos que constituye una aproximación fundamental, necesaria, para no caer, luego, en el olvido de lo que somos en la naturaleza ni de lo que somos por la naturaleza; podríamos denominarlo humanismo de pertenencia. Desarrollar este planteamiento proporciona un nivel imprescindible para la construcción de una teoría de la educación, antes de plantear un plan curricular y de discutir denominaciones disciplinares.

En muchos de los aspectos aludidos está en juego lo que podríamos llamar cultura corporal, cultura del cuerpo; los problemas ahí son culturalmente radicales, aunque la geografía léxica sea todavía muy imperfecta. No parece que se encuentre bien estructurado el espacio de la experiencia corporal - del que la educación física y el deporte constituyen dos especies- dentro del mapa de la cultura del cuerpo. La vida de los humanos, por más compleja que aparezca y por más diversificada que se encuentre en las ocupaciones, sigue siendo vida encarnada; la corporeidad proporciona rasgos de identificación y diversificación cultural. 


\subsection{La corporeidad en la dinámica educativa primaria}

La acción de formación no se encuentra directamente relacionada con un diseño de acción sobre otro, sino con la intervención que crea un contexto para la acciónexperiencia de alguien; dicho en otros términos, crear condiciones para que otro sea. Primariamente la acción de formación crea contextos para la experiencia entendiendo por tal todo suceso relacional vivido por el sujeto en su transacción con el entorno. El sujeto esquematiza tales sucesos dentro de un proceso de reconocimiento y los memoriza valorados, produciéndose la experiencia, transformándolos en recursos desde los que cumple su función de actor en nuevas situaciones.

La experiencia humana básica se construye, pues, dentro de un proceso relacional en el mundo con los humanos donde, primariamente, se asocian percepciones, desde toda la periferia sensorial, y estados emocionales positivos-negativos; la relación primaria se encuentra asociada a sutiles intercambios emocionales (Greenspan y Benderly, 1997) que constituyen el cimiento de la arquitectura de la actividad mental. Frente a este planteamiento se encuentra la fractura tradicional entre razón y emoción, fractura que impide ver los mecanismos mediante los que interactúan la afectividad y el entendimiento y con los que se construye la identidad personal y comunitaria.

A partir de esta modalidad de experiencia básica se inicia la trayectoria experiencial del sujeto en la cultura y su formación dentro del espacio intersubjetivo que tiene como marco el mundo de la vida. Son muchas las investigaciones que confirman que las emociones intervienen en la creación, organización y coordinación de las más importantes funciones mentales (Damasio, 1999), especialmente las responsables de las habilidades sociales y el desarrollo intelectual (Greenspan y Thorndike-Greenspan, 1997). Tal vez haya jugado un papel primordial en este cambio de perspectiva el desarrollo de los estudios sobre el espectro autista, donde la fisiología dificulta o impide en quienes lo padecen el tránsito adecuado por las experiencias de emocionalidad intersubjetiva. Estamos ante un proceso regulador primario para orientar la atención sobre el mundo y un importante mecanismo discriminador de objetos de experiencia.

Sospecho que la conciencia ha prevalecido en la evolución porque el conocimiento de los sentimientos causados por las emociones fue indispensable para el arte de la vida, y porque el arte·de la vida conoció un éxito considerable en la historia de la naturaleza... para que pudiéramos sentir la vida (Damasio, 1999, 40).

En este nivel primario o de formación temprana el lenguaje coloquial habla de pautas de crianza (Pérez Alonso-Geta, 1996), entre las que una simple mirada advierte que se trata de cuidados corporales y patrones de comunicación afectiva, una especie de integración entre estimulación cognitiva y emocional mediante la participación en el entorno. La unidad fundamental primaria de comportamiento 
mental humano se configura así en la relación entre un sentimiento y una acción que entra en el espacio sentiente del niño; cuando esto ocurre, aprende a usarla para reconocer, discriminar, compartir, valorar... La advertencia de esta relación establecida por el niño se torna en pivote para nuevos pasos en la actividad mental. Es esa interacción en contexto intersubjetivo la que instituye la zona de construcción del sujeto. Desde esta convicción se construye la planificación de acción terapéutica en niños con déficit tanto emocionales como sociales o intelectuales.

Tan importante para la trayectoria experiencial del sujeto es esta situación que la propia biología ha dispuesto la tendencia innata al vínculo. No se trata de un vínculo social cualquiera, sino del dispuesto para la mutua satisfacción, una urdimbre afectiva mediada por el contacto humano en el que el primer reconocimiento es a partir de apariencias, un vínculo intraespecífico evolutivamente dispuesto (Bowlby, 1999). A veces pensamos que este tipo de vínculos se refieren únicamente a la etapa infantil, por entender que su manifestación primordial está referida a comportamientos que buscan proximidad; sin embargo, también se encuentra asociada al vínculo la experimentación de la seguridad necesaria para aventurarse a la exploración y al dominio del entorno, así como el retorno al foco del vínculo cuando se siente la necesidad de refugio.

El estrato sentimental está constituido por tramas donde se construyen las tendencias a la valoración y la acción, tramas de valoraciones de acciones, tramas de acciones que refuerzan su tendencia por estar inyectadas de emociones, emociones que hacen pegajosos y atractivos valores que se promueven con acciones. Una teoría general del vínculo afectivo entre el sujeto debiera vislumbrarse como un historial del proceso por el que se va transformando la regulación del afecto a medida que cambia el modo de vida en la red social de la que el individuo constituye un nodo (Feeney y Noller, 2001).

\subsection{Incorporación bimodal de la experiencia}

Ya hemos aludido a la experiencia como todo suceso relacional vivido por el sujeto en su transacción con el entorno. La experiencia es identificada como tal por un esquema de materiales de representación en el que encuentra su significado y por toda la trama de materiales cinestésicos del organismo, trama emocional, con la que completa su sentido-apreciación. La secuencia experiencial aparece, pues, como coordinación de coordinaciones entre paquetes de representaciones y tramas emocionales; la manera más inmediata y fundamental de mostrarse este carácter es la del Yo que se activa plenamente mediante vivencia de desasosiego o bonanza corporal. En circunstancias normales se produce en cada experiencia, por tanto, un reconocimiento dual de la misma: una identificativa, representacional, y otra valorativa, emocional; se trata de una asociación entre fenómenos del mundo y sentimientos.

Dentro de este carácter bimodal se va escribiendo la historia de nuestra experiencia y dibujando los rasgos idiosincráticos de nuestra particular personalidad, 
que se modula especialmente en relación con el cambio de las situaciones y con el curso del tiempo. Por lo tanto, la experiencia, en su doble vertiente representacional y de afectación subjetiva, se incorpora a la memoria del sujeto aportando discriminaciones y valoraciones sobre el mundo; y en este contexto bimodal de experiencia actuamos. La creación de situaciones para la implicación de los sujetos en contextos de acción e interacción y su incorporación subjetiva en forma de experiencia bifronte es el núcleo básico de la originalidad de la interacción en la especie humana y la forma más primaria de promover comportamiento en otro, el meollo de la acción de formación. Como afirma Dylan Evans (2002, p. 43) "todo apunta a que las emociones cognoscitivas superiores habrían sido diseñadas por la selección natural precisamente para ayudar a nuestros antepasados a enfrentarse a un entorno social cada vez más complejo".

\subsection{Las comunidades de práctica humanas}

De ahí lo inadecuado de caracterizar la humanidad en sus orígenes como horda de cazadores asesinos o grupos de fabricantes de armas. Washburn en 1956 proponía la caza-el carroñeo como actividad humana de transición desde el homínido, porque reunía todas las condiciones de un nuevo tipo de cooperación, una nueva modalidad de patrón asociativo, la cultura de matar para vivir como estilo de vida; otros, en cambio, han caracterizado al humano por su condición de fabricante de herramientas. Todo ello suena más bien a trasladar y discutir en el origen cuestiones ideológicas actuales. Lo cierto es que la locomoción bípeda es muy anterior a las huellas fósiles del fabricante de herramientas.

Al ponerse de pie, puede permanecer el régimen alimenticio, pero se transforma la manera de obtener el alimento; algunos entenderán que únicamente cambia la manera de procurarse la comida, pero lo que realmente cambia es nada menos que la configuración de los patrones de consecución de alimentación. El bipedismo es tan importante desde el punto de vista adaptativo que Richard Leakey (2000) califica de humanos a todas las especies que gocen de esta cualidad.

Con la posición bípeda la forma de la zona pelviana se extiende como para soportar todo el peso del cuerpo erguido. Este sistema de locomoción ventajoso parece estar asociado a eficacia en la captura del alimento y aparición de patrones de transporte, lo que podía favorecer actitudes comensalistas, compartición de alimentos y otras formas de complejidad en la vida social, elección de los trayectos en la búsqueda y la huida, memorización de informaciones ambientales útiles en el momento de la acción...; por lo tanto, debe andar en coderiva con aspectos valorables en el cerebro como "sentido del movimiento" (Berthoz, 1997).

La posición bípeda ha sido asociada por muchos antropólogos con la liberación de las manos para la construcción de herramientas, sin poner de relieve su relación con nuevas formas de cuidado de las crías y una respuesta de apego y contacto frente al estado de necesidad e infantilización prolongada. Esta vinculación de 
dependencia asociada al contacto, de cópula cara a cara, de hábitos de comensalismo en la alimentación... dan muestras de la complejidad en la interacción emocional, que se encuentra en coderiva evolutiva con los otros cambios en el patrón loco-comunicacional. De hecho la estructura nerviosa que en otros mamíferos anteriores se encontraba especializada en el control de la olfación (comunicación química preponderando sobre intercomunicación y relación por signos y movimientos corporales) es la que se fue transformando en el sistema que da soporte al aparato emocional y al sistema operativo de la memoria (Acarín, 2001). Crece a este respecto continuamente la advertencia de esa complejidad y elaboración de comportamiento social en los primates más próximos al hombre actual, complejidades que empezaron a mostrarse con los trabajos de Frans de Waal, los estudios de Dian Fossey sobre los gorilas de los montes Virunga o los de Goodall sobre los chimpancés; a partir de ahí se contaba con algún argumento para plantearse el "estilo de vida" (Kuper, 1996) de los primeros humanos. Otros (Mithen, 1998) entienden que los primeros indicios culturales debieron proceder no de una inteligencia técnica, sino de una inteligencia general aplicada a la toma de toda clase de decisiones.

Creemos, con otros muchos, que lo que más bien puede deducirse de estos planteamientos es el hecho de que los humanos se caracterizan como especie por formar "comunidades de prácticas", es decir, no habría duda de que desde el primer momento nos caracterizó la especial naturaleza de nuestra inteligencia social, fundada no sólo en coordinaciones de respuestas sociales complejas sino en la posesión de una "teoría de la mente" o capacidad de construir creencias acerca de los estados mentales de otros y de organizar el comportamiento en función de esas estimaciones. Este hecho tiene especial importancia si consideramos la etapa de la vida infantil donde, sin la interacción social, ni puede adquirirse la competencia lingüística ni el resto de las habilidades sociales. Junto a la experiencia bimodal se sitúa, pues, la interacción social para la formación del comportamiento humano; dicho de otra manera, las experiencias bimodales primarias se encuentran asociadas al trato con otros humanos, a la inteligencia social para afrontar acciones y problemas sociales.

Como consecuencia de esta manera de ser nos vemos envueltos por todas partes en comunidades de práctica (Wenger, 2001). Aprender, formarse, es equivalente a participar en comunidades de práctica, porque la manera social de plantear el modo de vida de los humanos en todas las culturas hace que el aprendizaje sea equivalente a quedar comprometido en comunidades de prácticas. Una buena manera de intuir la importancia específica de lo que estamos diciendo es mirar hacia atrás, antes de que la tecnología invadiera ocultando el modo de vida humano y antes que el estudio de documentos invadiera ocultando el modo humano primario de aprendizaje, del que aquél es sólo un caso particular, una práctica de la comunidad lectoescritora. 


\subsection{Patrones primarios de acciones de formación en las comunidades de prácticas}

La teoría de la formación, decíamos, se construye habitualmente desde el sesgo del mundo de la educación formal, donde el aprendizaje es la consecuencia de procesos de enseñanza y de esfuerzos de atención y dedicación, el entorno no es natural sino institucional, la motivación no se encuentra asegurada y, sin todo esto, se produce el más inevitable y tremendo fracaso.

Pero, a tenor de lo que venimos comentando, la teoría de la educación debería plantear el análisis integral de la actividad, de la práctica, en las comunidades de práctica donde tiene lugar el desarrollo de la condición humana. Se trata de situaciones de interacción en las que son actores los humanos con su corporeidad específica, sus cuerpos con sus cerebros; ahí es donde tiene lugar la acción intersubjetiva que promueve comportamiento significativo (incorporación cultural) y donde se crean prácticas significativas de creación cultural (cultura objetiva); en tanto que proceso de incorporación constituye en sí misma proceso de formación. Por lo tanto, el proceso primario de formación está constituido por la implicación de los actores en tanto que seres vivos humanos en las prácticas, todas, de su comunidad. Y hay proceso de formación tanto si se da dicha implicación como si no tiene lugar, pues nuestra formación es consecuencia tanto de las competencias que adquirimos como de las que no tienen lugar, de las interacciones en las que quedamos implicados como de las que no se producen, porque el proceso de formación en la especie es un proceso necesario; lo contingente es la manera de discurrir en el interior de comunidades particulares. Por eso, es relevante para la formación del sujeto tanto la interacción como el abandono y la marginación.

La práctica a la que hacemos referencia es todo proceso a través del cual podemos experimentar el mundo y nuestro compromiso con él como significativo. La práctica de formación es precisamente la característica definitiva de la etología humana.
Naturalmente, para comprometernos en una práctica debemos estar vivos en un mundo en el que podamos actuar e interaccionar. Debemos tener un cuerpo con un cerebro que funcione lo suficiente para participar en comunidades sociales. Debemos tener maneras de comunicarnos con los demás. Pero centrarse en la prác- tica no equivale simplemente a adoptar una perspectiva funcional para contemplar las actividades humanas, incluyendo las actividades en las que participan muchos individuos. No aborda simplemente la mecánica — los aspectos prácticos- de con- seguir algo, individualmente o en grupo; no es una perspectiva mecánica. No incluye sólo los cuerpos (ni siquiera los cuerpos coordinados) y no incluye sólo los cerebros (ni siquiera coordinados), sino también lo que otorga significado a los movimientos de los cuerpos y al funcionamiento de los cerebros (Wenger, 2001, 75).

Tenemos, pues, un doble riesgo al construir una teoría general de la educación, hacerlo únicamente desde los mecanismos biológicos y etológicos que la hacen posible como práctica de formación, o hacerla meramente desde las apariencias etnográficas del comportamiento social en el que se encuentra el significado cultural de 
la práctica, olvidando toda la mediación corporal y cerebral mediante la cual se muestra que se trata de prácticas de seres vivos humanos dentro de la biosfera. El compromiso entre lo uno y lo otro estaría definiendo el campo de lo que anteriormente hemos llamado humanismo de pertenencia como marco de referencia para la elaboración de las ciencias humanas y sociales. En definitiva, la teoría general de la educación, antes de entrar en procesos de enseñanza-aprendizaje, debería comprender los "diseños y formas" de acción dentro de ese proceso vital de formación en el que acabamos de ser humanos y en este sentido ver la enseñanzaaprendizaje como un proceso vitalmente condicionado.

Curiosamente, entre las categorías de procesos primarios de formación en la zona de construcción del sujeto se encuentran algunos que en contextos escolares producen resistencia, como el proceso de formación a través de inmersión en la práctica de una comunidad o el de imitación, muy condicionado al modo de afiliación a la comunidad de práctica, o el de identificación, que la psicología suele interpretar en sentido individual y no tanto como identificación con las comunidades de afiliación. Pero también encontraríamos otros mejor valorados en esos contextos, como la exploración, la experimentación, el juego... En todos ellos un aspecto fundamental son "las ganas" de entrar en esa dinámica interactiva de formación. Guy Claxton $(2001,27)$ es contundente en este sentido: "el aprendizaje en sí mismo es un asunto intrínsecamente emocionalp; nosotros hemos partido en este apartado del carácter bimodal de la experiencia humana.

Cuiriosamente también, desde estos supuestos encontramos que la formación, como proceso vital primario, tiene lugar a lo largo de toda la vida, en el interior de todas las comunidades de práctica en las que nos comprometemos, como consecuencia de todas nuestras modalidades de afiliación-no-afiliación. Este sustrato se olvidó cuando se creó el "período de formación" dentro de los sistemas de enseñanza, es decir, cuando aparecen comunidades que introducen entre sus prácticas las propias de los sistemas de enseñanza.

Y no menos curioso es que los contenidos derivados de la formación en tanto que actividad intersubjetiva en las comunidades de práctica sean los que se asignan a las denominadas materias transversales del currículum, lo que está indicando que la inmersión en la práctica de los profesores debiera arrancar de la inmersión en la condición humana para dejarlos dispuestos a la creación de actividades que introduzcan en el conocimiento de un campo científico al tiempo que ayudan a sus alumnos a conocerse mejor y a conocer mejor el mundo. Mejorar la relación experiencial global entre el hombre y la biosfera es el objetivo de la educación ambiental; resulta curioso que, siendo el problema tan radical y tan radicalmente cultural, no se identifique como contenido de la programación educativa más que cuando se dan cortes transversales en el diseño curricular. 


\section{CONCLUSión: LA MTRADA EN EL ESPEjO}

Newman, Griffin y Cole (1991), en contexto y terminología vigotskiana, utilizaron la expresión "zona de construcción de conocimiento" para dar cuenta de los cambios cognitivos en los sujetos; nosotros, en este momento, preferimos hablar de "zona de construcción del sujeto", puesto que en la misma zona y situación en la que se producen los cambios cognitivos tienen lugar también otros cambios y configuraciones, como los relativos a la identidad del sujeto; por eso introducíamos también el término comunidades de práctica. En todos los casos estamos aludiendo a que la construcción del sujeto, que hemos calificado de autopoiesis, siempre tiene lugar en un entorno; más aún, su identidad se expresa precisamente en forma de pauta de relación con el medio activo influyente con el que interacciona. Dentro de los procesos descritos, todos los individuos de todas las culturas nos sentimos vivir y nos experimentamos como sujetos en singular. Tenemos esta experiencia de manera natural, una veces de manera exuberante, otras dramática, pero siempre como subjetividad unificada. Ésta es la raíz desde la que consideramos que todos los demás comparten el mismo reconocimiento y sentimiento de ser, al tiempo que marcamos la diferencia de los demás y la singularidad propia.

Las ciencias y las artes de todos los tiempos han buscado iluminar esa identidad de lo humano. Como consecuencia de las diferentes perspectivas y métodos de consideración, en numerosas ocasiones nos la han entregado rota en fragmentos, incluso en algunos casos, como en el denominado posmodernismo, no sólo en pedazos sino disuelta y convertida en ecos de palabras. Entre tanto, todos y cada uno de nosotros tiene en esa identidad su problema más próximo y con frecuencia constituye el meollo de nuestras conversaciones: ¿quiénes somos para que nos esté pasando lo que nos está pasando?

La última obra de Edgar Morin (2001), considerada por el autor la síntesis de una vida, lleva por lema La bumanidad de la bumanidad. La identidad bumana. Demuestra ahí el autor la necesidad de afrontar el tema desde la integración de perspectivas y "en otro lugar de encuentro", en cierta medida saliendo de los compromisos intelectuales contraídos en nuestros respectivos campos de conocimientos y de nuestros compromisos sociales e ideológicos habituales. En el nuevo lugar debemos encontrarnos con el humano "genérico". La gran sorpresa de ese encuentro es que lo que verdaderamente compartimos no son las ideas, ni las culturas, ni las especialidades científicas, ni los cometidos sociales, ni los lugares de residencia, ni los parentescos sanguíneos... sino el origen. El punto de encuentro lo proporciona la condición humana de nuestro cuerpo, el componente más olvidado y menospreciado, desarticulado y viviseccionado de la cultura occidental. Las cicatrices del cuerpo, consecuencias de nuestras locuras de Homo sapiens-Homo demens, que generaron la esclavitud, los campos de concentración, los genocidios... muestran la humanidad y las inhumanidades. En ese lugar de encuentro, mirándonos y tocándonos, es donde debemos formular la pregunta por la identidad. 
Si volvemos al terreno pedágógico y tomamos la intersubjetividad como el espacio en el que tienen lugar las relaciones por las que los humanos terminamos de hacernos en la cultura, antes o por delante de las escuelas y de los mastodónticos sistemas de enseñanza, parece lógico pensar que el aprendizaje y los contenidos, en ese punto para el encuentro general, no tienen por norte ni el desarrollo tecnológico, ni el económico, ni la organización sociopolítica, sino que el polo está en la identidad y en la sostenibilidad de la identidad humana (Wenger, 2001), en el simple hecho de poder y tener que vivir con los demás en el mundo. No sólo tenemos, pues, que habérnoslas con la identidad de los sujetos, sino también con la supuesta identidad de las comunidades de práctica, cada vez más abiertas y plurales. Y en uno y otro caso es lógico preguntarnos por las razones y direcciones de identidad (Colom, 1999), siendo éste otro de los problemas fundamentales de una Teoría general de la Educación, porque siempre se dijo en este campo de conocimiento que sus límites se trazaban precisamente desde el horizonte de la construcción del sujeto.

La zona por donde se empieza a construir el sujeto es su zona de convivencia y las razones de identidad y los problemas que ella genera tienen que ver con esa zona de residencia. Pero si no nos acercamos a nuestra identidad abriendo nuestros lugares de experiencia para verlos reflejados en el espejo del otro, donde nos vemos iguales, nunca dispondremos de un verdadero lugar de encuentro. Nuestro lugar de experiencia es local, pero nuestro lugar de reflejo ha de ser global; sólo así lo será también nuestra reflexión. Precisamente una forma de alcanzar y conducir la imprescindible "globalización" en nuestra reflexión sobre la educación es, por muy paradójico que parezca, deconstruir los numerosos y variados estratos que la evolución cultural ha ido creando hasta llegar a los sustratos más básicos del proceso educativo en la especie humana.

En la espontaneidad de la conversación mostramos nuestra identidad desde el contenido unificado de nuestra propia conciencia y respecto de un mundo que se encuentra frente a nosotros por conocer. Como buenos realistas ingenuos, hemos pensado que el mundo es independiente de nuestras mentes y las cosas son como aparecen; por esta vía no terminamos de comprender nuestra capacidad de conocimiento ni de convencernos que el mundo de la vida lleva la marca de nuestra propia estructura. Junto a esa ingenuidad, que atribuimos al juicio vulgar y de la que pretende librarse la ciencia, hay otra mucho más actual y perniciosa para el mundo de la educación: considerar que nuestra identidad es meramente una operación de cómputo, producto de una máquina inteligente que podemos simular construyendo máquinas con inteligencia artificial. Estas dos ingenuidades conllevan grandes dificultades y obstáculos para comprender no sólo el mundo sino también el carácter intersubjetivo de la construcción de la identidad humana (Varela, Thompson y Rosch, 1992).

Siempre pensamos que formarse una identidad depende de un proceso de enseñanza-aprendizaje y que aprender es un proceso individual, con principio y final, que se sitúa en paralelo al resto de nuestras actividades ordinarias. No 
terminaremos de entender cómo se forma nuestra identidad personal si no advertimos que aprender es un carácter de la naturaleza humana y no una tarea que se asume en el interior de instituciones y que comprender es un fenómeno fundamentalmente social que, en sus aspectos vitalmente más decisivos, se encuentra asociado no tanto a las cosas que estudiamos cuanto al conjunto integral de las cosas que hacemos. A fuerza de ver y analizar la educación y la cultura dentro del modelo académico, las entendemos sobre todo a partir de sus manifestaciones objetivas, las grandes creaciones culturales y los buenos o malos resultados escolares. Pero la educación y la cultura con las que configuramos nuestra identidad se encuentran asociadas, como hemos indicado, a comunidades de práctica, a múltiples y diversas formas de afiliación, que son parte integral de nuestra vida diaria. La práctica en comunidad compone el conjunto de idas y venidas de nuestra propia historia al tiempo que la historia de la comunidad; y no creemos que sea posible reducir una y otra a un mero catálogo de narraciones.

Terminamos. Hemos visto la utilidad de, en lugar de descomponer, retroceder en el tiempo e ir despojando al ser humano de las superestructuras que la evolución cultural fue poniendo a su disposición, aunque ocultando bajo su sombra la condición humana. Si quitamos el ropaje de la complejidad civilizatoria asociada al progreso tecnológico, la bruma de conceptos que hizo posible la amplia memoria externa acumulada en la escritura, curiosamente la condición que se revela, sorprendiendo por sus calidades, no es tanto la pobre cultura de la piedra, sino la maravilla de una comunicación comunitaria mediante la construcción de "creencias" acerca de los estados mentales de los interlocutores, que en otro lugar hemos llamado teoría de la mente, y de una curiosidad dirigida al entorno que permitió ser el único mamífero capaz de colonizar todos los ecosistemas de la Tierra.

La cultura en sus formas primarias se compone de prácticas donde se funde el conocimiento y la creatividad para convertir el entorno local en morada. Toda la vida se ocupará, a través de la creación de cultura, en "arreglar la casa". Esta afiliación comunitaria "local" es la fuente primaria de identidad y la primaria demostración de nuestra inteligencia natural (Mithen, 1998), aunque la comprensión de la propia identidad y de la condición de humanidad pase hoy necesariamente por "ampliar la casa", por el empeño en dilucidar el enigma de la multiculturalidad (Baumann, 2001).

La tarea fundamental de la reflexión sobre la educación es precisamente estar atento a todo ese recorrido de los humanos como especie dentro del mundo de la vida, recorrido que empieza precisamente reproduciendo el diseño de la especie en un cuerpo que no puede sobrevivir sino incorporándose a un espacio relacional compuesto por comunidades de humanos; ahí toma modos de ser y estilos de hacer, desarrolla unas capacidades y se inhibe en otras; allí es donde construye la obra más maravillosa, compleja, exclusiva, participada, comprometida, afiliada, poliédrica, a la que todos señalamos como identidad. Construir esa identidad es el objetivo de todo el proceso de formación y comprender ese proceso es el objetivo fundamental de la teoría de la educación. 
JOAQUÍN GARCÍA CARRASCO Y ÁNGEL GARCÍA DEL DUJO

LA TEORÍA DE LA EDUCACIÓN EN LA ENCRUCIJADA

\section{BIBLIOGRAFÍA}

ACARÍN, N. (2001) El cerebro del rey. Una introducción apasionante a la conducta bumana. Barcelona, RBA.

ASENSIO AGUILERA, J. M. (1997) Biología y educación. Barcelona, Ariel.

BAUMANN, G. (2001) El enigma multicultural. Un replanteamiento de las identidades nacionales, étnicas y religiosas. Barcelona, Paidós.

BECKER, G. (1964) Human Capital. Chicago, The University Chicago Press.

BERTHOZ, A. (1997) Le sens du mouvement. Paris, Odile Jacob.

BOURDIEU, P. y PASSERON, J. C. (1977) La reproducción: elementos para una teoría del sistema de enseñanza. Barcelona, Laia.

BOWLBY, J. (1999) Vinculos afectivos: Formación, desarrollo y pérdida. Madrid, Morata.

CARBONELL ROURA, E. (2002) Atapuerca: antes y después de la aparición de la complejidad humana, en V.AA. El lenguaje y la mente bumana. Barcelona, Ariel.

CARR, W. (1996) Una teoría para la educación. Hacia una investigación educativa crítica. Madrid, Morata.

CASTILLEJO BRULL, J. L.; VÁZQUEZ GÓMEZ, G.; COLOM CAÑELLAS, A. J. y SARRAMONA LÓPEZ (1993) Teoría de la Educación. Madrid, Taurus.

CLAXTON, G. (2001) Aprender. El reto del aprendizaje continuo. Barcelona, Paidós.

COLOM, F. (1999) Razones de identidad. Pluralismo cultural e integración política. Barcelona, Anthropos.

COLOM CAÑELLAS, A. J. (1982) Teoria y metateoría de la educación. Un enfoque a la luz de la teoría general de sistemas. México, Trillas.

COLOM CAÑELLAS, A. J. (2002) La (de)construcción del conocimiento pedagógico. Nuevas perspectivas en teoría de la educación. Barcelona, Paidós.

DAMASIO A. R. (1996) El error de Descartes. La emoción, la razón y el cerebro bumano. Barcelona, Editorial Crítica-Drakontos, Mondadori.

DAMASIO, A. S. (1999) Le sentiment même de soi. Corps, émotions, conscience. Paris, Odile Jacob.

ENKVIST, I. (2000) La educación en peligro. Madrid, Grupo Unisón.

ESTEVE ZARAZAGA, J. M. (1979) Lenguaje educativo y teorias pedagógicas. Madrid, Anaya.

EVANS, D. (2002) Emoción. La ciencia del sentimiento. Madrid, Taurus.

FEENEY, J. y NOLLER, P. (2001) Apego adulto. Bilbao, Desclée de Brouwer.

FLECHA, R. (1988) Dos siglos de educación de adultos. De las Sociedades de Amigos del País a los modelos actuales. Barcelona, El Roure.

FOSSEY, D. (1985) Gorilas en la niebla. Barcelona, Salvat.

FREUD, S. (1986) El malestar de la cultura. Madrid, Alianza Editorial.

GARCÍA CARRASCO, J. y GARCÍA DEL DUJO, A. Teoría de la Educación. Volumen 1. Educación y acción pedagógica. Salamanca, Ediciones Universidad de Salamanca.

GIMENO SACRISTÁN, J. y PÉREZ GÓMEZ, A. (1993) Comprender y transformar la enseñanza. Madrid, Morata.

GOODALL, J. (1986) En la senda del hombre. Vida y costumbres de los chimpancés. Barcelona, Salvat.

GREENSPAN, S. I. y BENDERLY, B. L. (1997) El crecimiento de la mente y los ambiguos origenes de la inteligencia. Barcelona, Paidós. 
GREENSPAN, S. y THORNDIKE-GREENSPAN, N. (1997) Las primeras emociones. Las seis etapas principales del desarrollo emocional durante los primeros años de la vida. Barcelona, Paiclós.

JAEGER, W. (1981) Paideia: los ideales de la cultura griega. Madrid, Fondo de Cultura Económica.

KUPER, A. (1996) El primate elegido. Naturaleza humana y diversidad cultural. Barcelona, Drakontos-Crítica.

LEAKEY, R. (2000) El origen de la bumanidad. Madrid, Debate.

LERENA ALESÓN, C. (1983) Reprimir y liberar: critica sociológica de la educación y de la cultura contemporáneas. Madrid, Akal.

MATURANA, H. y VARELA, F. (1990) El árbol del conocimiento. Las bases biológicas del conocimiento bumano. Madrid, Debate.

MITHEN, S. (1998) Arqueología de la mente. Origenes del arte de la religión y de la ciencia. Barcelona, Grijalbo-Mondadori.

MORIN, E. (1974) El paradigma perdido. Ensayo de bioantropología. Barcelona, Kairós.

- (2001) La méthode. 5. L'humanité de l'humanité. L'identité humaine. Normandi, Seuil.

ORTEGA RUIZ, P. (coord.) (1997) Educación moral. Murcia, Cajamurcia.

ORTEGA RUIZ, P. y MÍNGUEZ VALLEJOS, R. (2001) Los valores en la educación. Barcelona, Ariel.

PEREZ ALONSO-GETA, P. M. (1996) Valores y pautas de crianza familiar: el niño de 0 a 6 años. Madrid, Fundación Santa María.

PÉREZ RANSANZ, A. R. (1993) Modelos de cambio científico, en MOULINES, C. U. (ed.). La ciencia: estructura y desarrollo. Madrid, Trotta.

PETERS, R. S. (1969) El concepto de educación. Buenos Aires, Paidós.

PUIG ROVIRA, J. M. (1986) Teoría de la educación. Una aproximación sistémico-cibernética. Barcelona, PPU.

RODIGUEZ DELGADO, J. M. (1972) Control físico de la mente. Hacia una sociedad psicocivilizada. Madrid, Espasa Calpe.

RUIZ PAZ, M. (1999) Los límites de la educación. Madrid, Grupo Unisón.

SAN JOSÉ, A. (2001) El espacio del profesor. Madrid, Grupo Unisón.

SANVISENS MARFULL, A. (1983) Concepción sistémico-cibernética de la educación, en V.AA. (1983) Teoría de la educación I. El problema de la educación. Murcia, Límites.

WASHBURN, S. L. y MOORE, R. (1986) Del mono al hombre, un estudio sobre la evolución bumana. Madrid, Alianza.

WAAL, F. de (1982) La politica de los chimpancés. Madrid, Alianza.

VARELA, F. J.; THOMPSON, E. y ROSCH, E. (1992) De cuerpo presente. Las ciencias cognitivas y la experiencia bumana. Barcelona, Gedisa.

WENGER, E. (2001) Comunidades de práctica. Aprendizaje, significado e identidad. Barcelona, Paidós. 